\title{
The Importance of Perception and Imagination in Designing 3D Image
}

\section{Kepentingan Imaginasi dan Persepsi Dalam Merekabentuk Imej 3D}

\author{
Mohd Khairulnizam Ramlie ${ }^{1}$, Hanafi Moh Tahir ${ }^{2} \&$ Ahmad Sofiyuddin Mohd Shuib \\ ${ }^{1,2,3}$ Universiti Teknologi MARA Perak Branch, Seri Iskandar Campus, \\ 32610 Seri Iskandar, Perak, MALAYSIA \\ Authors' email: nizamramlie@gmail.com ${ }^{1} \underline{\text { hanaf185@uitm.edu.my }}^{2}, \underline{\text { sofiyuddin@yahoo.com }}^{3}$
}

Published: 7 September 2018

\begin{abstract}
3D animation and modelling has been known as one of the main subjects in the field of Arts and Design in Malaysia. This subject is applicable to all fields in the Faculty of Art and Design, including courses offered at the Universiti Teknologi MARA. As we all know, this 3D subject requires students to have great visual skills. In order to produce an attractive design, students need to have good memory, cognitive, and perceptual skills. However, problems arise when final year students of graphic design and digital media departments are found to be incompetent in that aspect. Thus, this study aims to investigate the problems and identify the most suitable time to apply so that the problems can be solved when students are in their final year of study.
\end{abstract}

Keywords: 3D Image, Education, Multimedia, Cognitive skills

\begin{abstract}
ABSTRAK
Salah satu subjek yang utama dalam bidang seni lukis \& seni reka di Malaysia secara am nya adalah $3 D$ animation dan $3 d$ modelling. Subjek ini terpakai untuk semua bidang di dalam fakulti seni lukis \& seni reka termasuklah kursus yang di tawarkan di Universiti Teknologi MARA. Seperti sedia maklum subjek 3 d memerlukan kemahiran visual pada setiap pelajar untuk menghasilkan suatu rekabentukyang baik. Untuk menghasilkan suatu rekabentuk yang menarik, pelajar memerlukan kemahiran kognitif, memori dan persepsi yang baik. Permasalahan yang sering terjadi adalah apabila pelajar tahun akhir daripada jabatan grafik \& media digital tidak sepenuhnya mahir di dalam aspek tersebut. Dasar kepada kemahiran ini akan dikaji dan di kenalpasti tentang masa yang sesuai untuk di terapkan dan difahami sepenuhnya agar masalah dapat diselesaikan ketika pelajar berada di tahun akhir pembelajaran.
\end{abstract}

Kata kunci: Imej 3D, Pendidikan, Multimedia, Kognitif

eISSN: 2550-214X (C) 2018. The Authors. Published for Idealogy Journal of Arts and Social Science by UiTM Press. This is an Open Access article distributed under the terms of the Creative Commons Attribution-NonCommercial-NoDerivatives License (http://creativecommons.org/licenses/by-nc-nd/4.0/), which permits non-commercial re-use, distribution, and reproduction in any medium, provided the original work is properly cited, and is not altered, transformed, or built upon in any way.

\section{PENGKATEGORIAN IMEJ 3D}

Secara umumnya bentuk model 3D sediada mempunyai beberapa kategori, perkara asas yang perlu dipertimbangkan adalah pengkategorian bentuk-bentuk 3D agar ia dapat dikategorikan pada beberapa tahap yang berbeza (López-Sastre, García-Fuertes, Redondo-Cabrera, Acevedo-Rodríguez, \& Maldonado-Bascón, 2013). Perkara ini penting memandangkan bilangan model 3D yang telah dihasilkan kini berkembang dengan pesat seiring dengan kepantasan evolusi yang berlaku di dalam perkasasan dan perisian grafik untuk menghasilkan model 3D dan imej manipulasi (Adán, Salamanca, \& Merchán, 2012). Perkara ini dapat dikaitkan dalam kes imej 2D di mana Local Feature digunakan untuk proses pengkategorian objek. Local Feature ini merujuk kepada corak atau struktur yang berbeza yang terdapat di dalam sebuah imej, seperti titik, ruang atau bahagian imej kecil. Ia biasanya dikaitkan 
dengan gabungan imej yang berbeza dari segi persekitannya, tekstur, warna atau keamatan. Oleh kerana itu, Local Feature juga boleh digunakan di dalam kaedah pengkategorian model 3D untuk mengklasifikasikan sesuatu objek (López-Sastre et al., 2013).

Di dalam kes untuk mengenalpasti objek 3D dengan lebih mendalam pula, 3DSPMK (3D Spatial Pyramid Matching Kernel) telah di perkenalkan oleh (Redondo- Cabrera, Lopez-Sastre, AcevedoRodriguez, \& Maldonado-Bascon, 2012). Bagaimanapun, kajian ini telah di teruskan oleh (LópezSastre et al., 2013) dan telah merumuskan formula baru untuk meningkatkan prestasi pengiktarafan di dalam pengelasan imej 3D.

\section{PERSEPSI TERHADAP IMEJ 3D}

Di dalam proses pengkategorian imej 3D, persepsi terhadap 3D visual adalah antara isu yang perlu di ambil perhatian yang mendalam kerana persepsi terhadap visual 3D adalah berbeza pada setiap individu yang melihat dan memberi kesan kepada pengiktirafan terhadap sesuatu imej 3D tersebut. Di antara masalah asas persepsi visual terhadap bentuk $3 \mathrm{D}$ adalah corak ransangan optikal yang kabur (Todd, 2004), kekaburan ini telah dibuktikan dari sudut analisis matematik. Walaupun kekaburan terhadap visual 3D adalah salah satu dari halangan persepsi yang tinggi, terdapat banyak aspek lain didalam struktur 3D visual yang tidak dijelaskan secara spesifik. Corak prestasi yang sama telah dikenalpasti daripada perbandingan yang telah dibuat antara kajian empirikal dengan permerhatian manusia.

Walaubagaimanapun, secara asanya, maklumat visual diwakili oleh gambar 2D di retina, tetapi minda kita mengubah input daripada retina kepada persepsi untuk kita dapat melihat persekitaran secara 3D (Finlayson, Zhang, \& Golomb, 2017). Walaupun banyak kajian telah dijalankan untuk gambaran 2D spasial atau persepsi, perkara ini tetap belum dapat dikenalpasti bagaimana proses ini berinteraksi dalam korteks visual manusia. Perwakilan spatial beransur-ansur berubah dari domain 2D ke 3D secara seimbang disepanjang proses visual hierarki.

\section{IMAGINASI VISUAL DAN MEMORI.}

Persepsi terhadap visual 3D ini juga boleh dikaitkan dengan Imaginasi Visual Dan Memori. Sebuah kajian yang telah di buat oleh (Atwood, 1971) menunjukkan bahawa persepsi terhadap visual yang tidak relevan akan menganggu pembelajaran yang dijalankan secara lisan, gangguan ini disebabkan oleh imej yang tidak selari dengan pendengaran. Melalui kajian ini, keputusan yang diperolehi memberi maklumat tentang wujudnya komponen visual sebenar di dalam pengantaraan sesuatu imaginasi. Sebuah model teori yang dibentangkan melalui kajian ini, sistem visual dan sistem pendengaran lisan boleh dibezakan. Sistem visual mengawal persepsi visual dan imaginasi visual. Selain daripada itu, sistem visual dan verbal-auditori dikaitakan fungsinya dengan operasi merakam maklumat. Oleh kerana itu, persepsi seseorang itu amat berkait rapat dengan sistem visual samada 2D ataupun 3D.

Imaginasi ,persepsi dan memori berkait rapat dengan kognitif manusia. Kieron Philip O'Connor \& Frederick Aardema (2005) telah cuba untuk menempatkan imaginasi dalam kesedaran yang lengkap dengan domain Pra Kognitif yang juga dipanggil prescience, visi masa depan, penglihatan masa depan adalah kemampuan dugaan psikik untuk melihat peristiwa di masa depan. Walaubagaimanapun, tiada bukti saintifik yang diterima bahawa pra-kognitif wujud dan ia secara meluas dianggap sebagai pseudosains. Walaupun demikian, ramai yang percaya pada prakognitif ini. Kognitif, tindakan mental atau proses memperoleh pengetahuan dan pemahaman melalui pemikiran, pengalaman, dan deria, dan Meta- kognitif. Pembahagian ini telah dibuat dan kajian di bahagian pertama adalah mengkaji secara ringkas falsafah tradisional dan konsepsi psikologi imaginasi. Secara majoritinya dapat dilihat persepsi dan imaginasi adalah kategori yang berasingan dengan melaksanakan fungsi yang berbeza. 
Kenyataan ini disokong oleh (Markson \& Paterson, 2009) mengalihkan pandangan daripada seorang yang sedang berbicara dapat meningkatkan prestasi kanak-kanak dan orang dewasa dalam pelbagai tugas kognitif. Dalam kajian yang dijalankan, keputusan menunjukkan bahawa dengan mengekalkan fokus mata bersama seseorang yang sedang berbicara, dalam masa yang sama individu lain menganggu imaginasi, imaginasi tersebut tidak terganggu dengan ransangan visual yang lain. Kesimpulanya, mengalihkan pandangan daripada seseorang yang sedang berbicara memberi kelebihan terhadap prestasi kognitif, dengan mengalihkan pandangan dari maklumat visual yang tidak relevan, dan menganggu proses interaksi sosial yang terlibat dalam perbualan.

Di dalam perbincangan prosedur atau konsep untuk pembelajaran pula, teknik pembelajaran yang berkesan adalah dengan membayangkan prosedur atau konsep berbanding dengan pembelajaran secara konvensional, dengan itu ia akan menghasilkan kesan imaginasi tersebut (Leahy \& Sweller, 2004). Walaubagaimanapun, hipotesis tentang kepentingan pembelajaran melalui imaginasi sebagai Teknik pengajaran bergantung kepada mod yang dipersembahkan.

Sistem visual memproses objek keseluruhannya seperti bentuk dan warna dan sifat spatial seperti lokasi dan hubungan ruang dalam sistem yang berbeza, dan bukti neuropsikologi mendedahkan bahawa gambaran mental menghormati perbezaan ini (Kozhevnikov, Kosslyn, \& Shephard, 2005). Hasil kajian juga menunjukkan bahawa visualisasi objek memproses imej secara holistik sebagai satu unit persepsi, manakala visualisasi spatial menjana dan memproses imej secara analitik, sebahagian demi sebahagian. Di samping itu, didapati saintis dan jurutera professional lebih suka memilih imejan ruang dan strategi spatial, sedangkan para seniman visual professional di dalam imejan objek lebih suka kepada stratergi yang berasakan objek nyata.

Secara tradisionalnya, permukaan 3D model dibina daripada informasi komputer yang digunakan untuk menghasilkan imej baru. Sebagai langkah alternatif, ia menggabungkan piksel yang sesuai dari pandangan yang dirakam, ia mungkin bagi mengelak daripada keperluan model 3D yang sempurna dan untuk mendapatkan pandagan yang baru secara langsung. Sesuatu yang menarik untuk diperhatikan bahawa walaupun terdapat kekaburan dalam pembinaan semula geometri, pembetulan imej yang baru masih sering dijana (Pollefeys \& Van Gool, 2002).

\section{IMEJ 3D DAN SPATIAL}

Dalam beberapa tahun kebelakangan ini, grafik komputer telah membuat kemajuan yang hebat dalam menghasilkan model 3D (Pollefeys, 2004). Terdapat juga banyak teknik yang telah mencapai tahap kematangan dan sedang dialihkan kepada perkasasan komputer, dengan itu ia sangat berkemungkinan boleh mengambarkan adegan 3D yang kompleks dalam masa nyata. Revolusi ini adalah kerana kepentingan kehendak untuk menghasilkan visual 3D yang lebih kompleks dan realistik. Banyak objek yang diilhamkan daripada objek sebenar, oleh kerana itu ia lebih menarik untuk mendapatkan model secara langsung dari objek yang sebenar. Kualiti visual kini menjadi salah satu perhatian utama.

Semenjak diperkenalkan, bentuk atau nahu spatial telah berjaya digunakan sebagai pendekatan generatif untuk mewujudkan rekabentuk alternatif di dalam pelbagai bidang seperti seni visual, seni bina atau kejuruteraan (Hoisl \& Shea, 2011). Walaubagaimanapun, hanya beberapa nahu spatial tiga dimensi yang telah dilaksanakan secara perkomputeran sehingga kini, dan kebanyakkannya adalah Kod Keras seperti peraturannya tidak boleh diubah tanpa pengaturcaraan semula, hanya beberapa perkara yang boleh diubah namun ianya terbatas. Oleh itu, penciptaan dan penggunaan nahu spatial diletakkan pada tahap yang lebih umum. Ini adalah untuk menyokong para pereka yang cenderung untuk berfikir secara spatial. Mendefinisikan nahu spatial secara lebih umum dan mudah untuk pemakaian peraturan pereka sendiri. 
Secara semulajadi dan intuitifnya, isyarat tangan yang ikonik adalah cara utuk menyampaikan maklumat spatial. Merakam dan mentafsir isyarat tangan yang ikonik akan menambah keupayaan pengguna untuk menyampaikan maklumat ruang melalui komputer. Kajian (Marsh \& Watt, 2016) menggunakan contoh- contoh daripada antara-muka 3D. Perkara pertama yang dibincangkan adalah pengguna mengalami kesukaran memahami ruang tiga dimensi. Melalui ujian mereka, pengguna di beri satu set stratergi yang boleh membantu para pengguna untuk lebih memahami persekitaran maya tiga dimensi. Set stratergi ini termasuklah rujukaan penggunaan spatial, gerak isyarat relatif, interaksi antara dua tangan, maklum balas multisensory, kekangan fizikal dan pengesanan kepala. Melalui hasil kajian ini, penyelidik telah menyatukan hasil sintesis yang banyak bertaburan, pemerhatian dan contoh ke dalam satu rangka kerja (framework) yang sama. Rangka kerja ini harus dijadikan salah satu panduan didalam kajian yang mungkin tidak biasa dengan isu reka bentuk di dalam input spatial. Mengenalpasti bidang interaksi ruang-bebas tiga dimensi juga adalah salah satu kajian yang berpotensi (Hinckley, Pausch, Goble, \& Kassell, 1994).

Penggunaan antara-muka yang nyata di dalam persekitaran rekaan yang baru menjanjikan kemudahan kepada interaksi pereka dengan model rekabentuk. Di dalam penjelasan tentang kesan antara-muka yang nyata, penyelidik membandingkan protokol reka bentuk yang sesi reka bentuknya berkejasama menggunakan sistem tabletop dan tangible user interface (TUI) dengan alat perkasaan biasa seperti papan kekunci, tetikus, paparan grafik antara-muka (GUI - Graphical User Interface). Ini adalah untuk mengenalpasti perubahan di dalam kognisi spatial pereka (Kim \& Maher, 2008). Banyak sistem tabletop bertujuan untuk membantu pereka dalam persiapan dan membangunkan model rekabentuk. Penggunaan (TUIs - Tangible User Iterface ) antara-muka nyata mengubah kognisi spatial para pereka, dan perubahan ini mempengaruhi proses rekabentuk dengan meningkatkan tingkah laku 'penemuan-masalah' yang membawa kepada reka bentuk yang kreatif.

Di dalam kajian yang lain pula, penyelidikan di buat untuk mengenalpasti kesan penggunaan antaramuka lakaran VR 3D berasaskan haptik pereka. Ini adalah untuk mengintegrasikan kognisi dan tindakan pereka yang baru bagi meningkatkan kreativiti dalam proses rekabentuk (Rahimian \& Ibrahim, 2011). Analisis protokol digunakan untuk membandingkan kolektif kognitif dan protokol rekabentuk kerjasama kepada pereka baru. Analisis ini menunjukkan bahawa antara-muka reka bentuk berasaskan haptik yang nyata dan ringkas meningkatkan kognitif dan aktiviti kerjasama pereka. Penambahbaikan ini juga meningkatkan penglibatan mereka dengan 'ruang-masalah' dan 'ruang-penyelesaian' yang membawa kepada kematangan artefak yang banyak. Penyelidikan yang telah di buat oleh (Rahimian \& Ibrahim, 2011) ini dapat membantu perkembangan persekitaran maya berasaskan haptik yang canggih dalam pendidikan seni bina dan bidang yang berkaitan.

Kemahiran yang tinggi di dalam 3D spatial adalah penting untuk seseorang itu berjaya di dalam beberapa kerjaya saintifik dan teknikal (Gerson, Sorby, Wysocki, \& Baartmans, 2001). Contohnya seperti jurutera yang sering berinteraksi melalui visual grafik. Oleh itu, sejak tahun 1998, perisian multimedia telah dibangunkan dalam bentuk modular, dan terdapat sembilan modul sedia ada setakat ini.

Salah satu matlamat utama di dalam pendidikan rekabentuk kejuruteraan grafik adalah pembangunan atau penambahbaikan kemahiran visualisasi spatial 3D (America Society For Engineering Education, 2010). Melalui sejarah, kemajuan dalam kemahiran spatial telah digunakan sebagai subjek sampingan untuk pendidikan grafik. Subjek ini dipelajari dalam beberapa semesta melalui teknik penyusunan secara manual. Oleh kerana kurikulum kejuruteraan berkembang dari masa ke masa, arahan grafik tradisional telah 'dipaksa' secara serentak dari dua arah.

Penekanan yang lebih diberikan kepada kemahiran pembangunan 3D spatial. Walaubagaimanapun, ramai pendidik dalam bidang grafik yang mempunyai kemahiran tinggi tidak mempunyai latihan secara formal dalam memahami kemahiran ruang, dan bagaimana ia dapat dikembangkan dengan berkesan (America Society For Engineering Education, 2010). 
Mengklasifikasikan beberapa jenis paparan visual-spatial dan perbincangan bagaimana paparan visual-spatial memaparkan kognisi tambahan. Perbincangan juga tentang gambaran keseluruhan proses persepsi dan kognitif yang terlibat semasa menggunakan paparan. Kaedah sains kognitif penting untuk reka bentuk paparan visual. Beberapa prinsip utama rekabentuk paparan yang terhasil daripada kaedah ini dikaji semula. Para saintis kognitif telah berjaya dalam mencirikan prestasi tugas yang jelas dengan paparan visual yang agak mudah. Namun begitu ia banyak cabaran dalam memahami penggunaan paparan kompleks untuk tugas yang tidak jelas (Hegarty, 2011).

\section{PEMINDAHAN IMEJ 2D KEPADA IMEJ 3D}

Penyelidikan sebelum ini menunjukkan, penggunaan yang cekap antara- muka pengguna grafik sangat bergantung kepada keupayaan manusia untuk kognitif spatial (Cockburn, 2004). Walaupun ia menarik untuk dikatakan bahawa gerakkan dari dua ke tiga dimensi antara-muka pengguna akan menambahbaik prestasi pengguna melalui memori spatial secara semulajadi, ia masih tidak jelas samada paparan tiga dimensi memberi manfaat ini. Di dalam ujian yang pernah dijalankan oleh penyelidik, sesetengah pengguna mengingati lokasi huruf abjad dengan lebih berkesan apabila menggunakan antara-muka $3 \mathrm{D}$ berbanding $2 \mathrm{D}$.

Daripada kajian yang telah dijalankan juga, ia menerangkan bahawa keberkesanan memori spatial tidak terjejas oleh kehadiran atau ketiadaan kesan perspektif tiga dimensi dalam paparan statik monokular. (keputusan yang sama di dapati dalam kajian (Markson \& Paterson, 2009).

Peranan memori di dalam membantu perhatian yang di peruntukkan dalam tingkah laku harian tidak difahami dengan baik. Dalam eksperimen yang dijalankan dengan imej dua dimensi (2D), terdapat bukti yang bercampur tentang kepentingan memori. Kerana konteks ransangan dalam eksperimen makmal dan perilaku harian sangat berbeza, peranan ingatan dalam carian visual dalam kedua-dua dimensi (2D) dan persekitaran tiga dimensi (3D) telah di kaji (Li, Aivar, Kit, Tong, \& Hayhoe, 2016). Melalui kajian itu juga, keputusan menunjukkan bahawa subjek yang dipelajari dari gabungan sasaran-ruang ada di dalam 3D tetapi tidak di dalam 2D. Pemerhatian semakin dibatasi ke daerah yang lebih relevan dengan pengalaman dari kedua-dua aturan. Walaubagaimanapun, pencarian objek kontekstual tempatan tidak digunakan oleh pengalaman awal. Penetapan secara kebetulan kepada konteks objek tidak semestinya menjamin kepada prestasi carian. Kelakuan dalam persekitaran 2D dan 3D adalah sama, walaupun terdapat penggunaan memori yang lebih besar dalam persekitaran 3D.

Satu siri eksperimen yang membandingkan paparan 2D, paparan 3D, dan paparan gabungan 2D/3D untuk anggaran kedudukan relatif, orientasi, dan jumlah kecenderungan tugasan diterangkan (Tory, Kirkpatrick, Atkins, \& Moller, 2006). Paparan 3D didapati sangat berkesan untuk anggaran navigasi dan kedudukan relatif apabila mendapat isyarat yang sesuai. Walaubagaimanapun, paparan 3D tidak berkesan untuk navigasi dan kedudukan yang tepat kecuali dalam keadaan tertentu, contohnya apabila kedudukan pandangan itu baik atau terdapat alat pengukur dipaparan. Gabungan paparan mempunyai prestasi yang baik, mengilhamkan keyakinan yang tinggi, dan membenarkan navigasi bersepadu secara semulajadi. Paparan 'clip plane' tidak berkesan untuk orientasi 3D kerana pengguna tidak boleh melihat lebih daripada satu keping 2D pada satu masa dengan mudah, dan terpaksa menukar penglihatan kepada setiap kepingan individu 2D. Faktor utama yang menyumbang kepada keutamaan paparan dan kegunaan adalah ciri tugasan, isyarat orientasi, halangan, dan jarak spatial yang di guna bersama. Persoalan timbul tentang i) bagaimana paparan antara-muka 2D atau 'clip plane' ini mempengaruhi penghasilan objek 3D oleh pelajar didalam bidang animasi 3D dan penghasilan objek cetakan 3D secara tepat dari segi ukuran dan sudut penglihatan mereka?

Teknologi permainan pada masa kini bukan hanya akan mengubah cara kita bermain, tetapi juga mengubah cara kita menghasilkan dan melihat seni, merancang produk baru, menganalisa data saintifik dan banyak lagi (LaViola \& Keefe, 2011). Kaedah perisian dan peralatan digunakan untuk membina model geologi spatial dan struktur jarang dalam persekitaran digital 3D. Permukaan bentuk-bebas yang diperolehi daripada bahagian-gaya (section-style) kawalan bingkai dan dikekang oleh medan-asas 
(field-based) pengukuran struktur digunakan sebagai alat bantuan rekabentuk yang secara langsung. Ini bertujuan untuk mempercepatkan dam memperkemaskan proses pembangunan model geologi 3D (Sprague \& de Kemp, 2005).

Melalui kajian empiris yang memberi tumpuan kepada kesan visualisasi tiga dimensi (3D) pada pembelajaran setakat ini jarang terjadi dan tidak konsisten. Menurut hipotesis keupayaan-penambahan, pelajar-pelajar berkeupayaan spatial yang tinggi kerana mereka mempunyai kapasiti kognitif yang cukup untuk pembinaan model mental mempunyai kelebihan (Huk, 2006). Sebaliknya, hipotesis kemampuan-pemampas mencadangkan, pelajar berkemampuan spatial yang rendah harus mendapat kelebihan gambaran grafik yang jelas kerana mereka mengalami kesukaran membina visualisasi mereka sendiri. Hanya pelajar yang mempunyai keupayaan spatial yang tinggi mendapat manfaat daripada kehadiran model 3D. Apabila menggunakan model 3D, para pelajar berkeupayaan spatial yang tinggi menganggap beban kognitif mereka rendah. Data menunjukkan bahawa kehadiran model 3D membebankan kognitif para pelajar yang keupayaan spatial mereka rendah, manakala pelajar yang mempunyai keupayaan spatial yang tinggi mendapat manfaat daripada para pelajar yang keupyaan spatial rendah kerana jumlah beban kognitif mereka kekal dalam had memori yang sedang digunakan.

Sistem 'tabletop' menyediakan platform untuk membangunkan novel sistem interaksi, termasuklah antara-muka pengguna yang nyata - Tangible User Interfaces (TUIs). Satu kajian yang lepas telah dijalankan tentang kesan sistem 'tabletop'. Kajian antara-muka pengguna yang nyata pada kognisi spatial, dan komunikasi rekabentuk pereka dalam rekabentuk kerjasama (Maher \& Kim, 2006). Kajian yang boleh memberikan kesan pada kognisi spatial pereka semasa menggunakan TUIs telah dijalankan.

Perbandingan ini dijalankan antara pereka. Pada satu bahagian adalah pereka yang menggunakan antara-muka penguna yang nyata (TUI) pada sistem 'tabletop', manakala satu bahagian lagi adalah pereka yang menggunakan antara- muka pengguna grafik (GUI) pada komputer meja biasa, yang mana menggunakan tetikus dan papan kekunci. Pereka diberi tugas reka bentuk konfigurasi di mana mereka memanipulasikan objek 3D untuk memenuhi spesifikasi reka bentuk. Penemuan awal daripada kajian itu, pereka yang menggunakan sistem 'tabletop' dengan TUIs menjelaskan tentang hubungan spatial diantara objek 3D dan menemui hubungan spatial yang tidak dijangka, manakala pereka yang menggunakan papan kekunci dan tetikus secara tradisional hanya menjelaskan mengenai objek 3D secara individu.

Antara-muka pengguna boleh meningkatkan prestasi tugas dengan memanfaatkan keupayaan manusia yang kuat untuk kognisi ruang. Peluang ini telah ditunjukkan oleh ekperimen terdahulu. Sesuatu yang menarik untuk dipercayai bahawa menyediakan fleksibiliti spatial yang lebih besar untuk perpindahan daripada imej rata 2D kepada antara-muka 3D akan meningkatkan lagi prestasi pengguna. Keberkesanan memori spatial dalam model fizikal dunia sebenar dan dalam kesepadanan sistem maya berasaskan komputer. Model yang berbeza mengubah kebebasan pengguna untuk menggunakan kedalaman dan perspektif di dalam susunan imej spatial untuk laman web. Keputusan menunjukkan bahawa prestasi subjek merosot dalam sistem fizikal dan maya kerana kebebasan mereka untuk mencari item dalam dimensi ketiga meingkat. Ukuran subjektif memperkuatkan ukuran pencapaian, menunjukkan bahawa pengguna mendapati antara-muka dengan dimensi yang lebih tinggi lebih kurang efisien dan kacau bilau (Cockburn \& McKenzie, 2002).

Rekabentuk antara-muka pengguna 3D adalah komponen yang kritikal bagi sebarang aplikasi persekitaran maya (virtual environment (VE). Tugas interaksi pengguna paling banyak dibahagikan ke dalam tiga kategori, navigasi, pemilihan/manipulasi, dan kawalan sistem. Kajian (Bowman, Kruijff, LaViola, \& Poupyrev, 2001) ini memfokuskan teknik yang sediada dan garis panduan praktikal untuk reka bentuk interaksi 3D dan mitos yang meluas. Pada akhirnya, kajian ini membincangkan secara ringkas tentang dua pendekatan untuk reka bentuk interaksi 3D dan beberapa contoh aplikasi dengan keperluan interaksi 3D kompleks. Ia juga membentangkan bibliografi dalam talian yang disaring sebagai rujukan. 


\section{KESIMPULAN}

Secara amnya dapat disimpulkan bahawa perkembangan kognitif pelajar dalam mempelajari suatu pembelajaran imej atau objek 3D perlu melalui asas yang kuat iaitu melatih cara berfikir untuk membantu kognitif pelajar di samping melatih pelajar menggunakan imaginasi dalam membentuk persepsi dalam melihat imej 3D mahupun untuk menghasilkan imej 3D. Secara khususnya, pelajar perlu menitikberatkan latihan mempelajari subjek-subjek asas seperti asas lukisan dan asas rupa bentuk berbanding terus menggunakan teknologi seperti tabel-top, telefon pintar atau komputer. Masalah yang sering dihadapi oleh pelajar dalam merekabentuk 3D dengan baik adalah kerana kurangnya daya kognitif, imaginasi dan persepsi yang betul kerana kurangnya perkara asas lukisan 2D dan 3D yang perlu dipelajari. Oleh kerana itu, melalui kajian ini didapati bahawa pelajar yang cemerlang dalam menghasilkan rekabentuk 3D dan imej 3D adalah terdiri daripada pelajar yang memahami konsep spatial 3D dan perspsi yang tepat melalui imaginasi dan daya kognitif yang tinggi. Namun begitu, kajian lebih mendalam perlu dilakukan dalam memastikan pelajar dapat memahami penggunaan perisian komputer dengan paparan 2D untuk menghasilkan rekabentuk 3D dengan lebih tepat melalui imaginasi dan lakaran 2D yang tepat.

\section{BIBLIOGRAFI}

Adán, A., Salamanca, S., \& Merchán, P. (2012). A hybrid human computer approach for recovering incomplete cultural heritage pieces. Computers and Graphics (Pergamon), 36(1), 1-15. https://doi.org/10.1016/j.cag.2011.10.003

Atwood, G. (1971). An experimental study of visual imagination and memory.

Bowman, D. A., Kruijff, E., LaViola, J. J., \& Poupyrev, I. (2001). An Introduction to 3-D User Interface Design. Presence: Teleoperators and Virtual Environments, 10(1), 96-108. https://doi.org/10.1162/105474601750182342

Cockburn, A. (2004). Revisiting 2D vs 3D Implications on Spatial Memory.

Cockburn, A., \& McKenzie, B. (2002). Evaluating the effectiveness of spatial memory in 2D and 3D physical and virtual environments. Proceedings of the SIGCHI Conference on Human Factors in Computing Systems Changing Our World, Changing Ourselves - CHI '02, (4), 203. https://doi.org/10.1145/503376.503413

Cognitive Psychology, 2(3), 290-299. https://doi.org/10.1016/0010-0285(71)90015-6

Finlayson, N. J., Zhang, X., \& Golomb, J. D. (2017). Differential patterns of 2D location versus depth decoding along the visual hierarchy. NeuroImage, 147, 507-516. https://doi.org/10.1016/j.neuroimage.2016.12.039

GeoInformatica, 9(1), 5-32. https://doi.org/10.1007/s10707-004-5620-8

Gerson, H. B. P., Sorby, S. A., Wysocki, A., \& Baartmans, B. J. (2001). The Development and Assessment of Multimedia Software for Improving 3-D Spatial Visualization Skills. Computer Applications in Engineering Education, 9(2), 105-113. https://doi.org/10.1002/cae.1012

Hegarty, M. (2011). The cognitive science of visual-spatial displays: Implications for design. Topics in Cognitive Science, 3(3), 446-474. https://doi.org/10.1111/j.1756-8765.2011.01150.x

Hinckley, K., Pausch, R., Goble, J. C., \& Kassell, N. F. (1994). A survey of design issues in spatial input. In Proceedings of the 7th annual ACM symposium on User interface software and technology - UIST '94 (pp. 213-222). https://doi.org/10.1145/192426.192501

Hoisl, F., \& Shea, K. (2011). Interactive, visual 3D spatial grammars. In Design Computing and Cognition '10 (pp. 643-662). https://doi.org/10.1007/978-94-007-0510-4_34

https://doi.org/10.1109/TABLETOP.2006.28

Huk, T. (2006). Who benefits from learning with 3D models? The case of spatial ability. Journal of Computer Assisted Learning. https://doi.org/10.1111/j.1365- 2729.2006.00180.x

Journal of Visualization and Computer Animation, 13(4), 199-209. https://doi.org/10.1002/vis.289

Kim, M. J., \& Maher, M. Lou. (2008). The impact of tangible user interfaces on spatial cognition during collaborative design. Design Studies, 29(3), 222-253. https://doi.org/10.1016/j.destud.2007.12.006

Kozhevnikov, M., Kosslyn, S., \& Shephard, J. (2005). Spatial versus object visualizers: A new characterization of visual cognitive style. Memory and Cognition, 33(4), 710-726. 
https://doi.org/10.3758/BF03195337

LaViola, J. J., \& Keefe, D. F. (2011). \{3D $\}$ spatial interaction: applications for art, design, and science. $\{A C M\}\{$ SIGGRAPH $\} 2011$ Courses, 1:1-1:75. https://doi.org/10.1145/2037636.2037637

Leahy, W., \& Sweller, J. (2004). Cognitive load and the imagination effect. Applied Cognitive Psychology, 18(7), 857-875. https://doi.org/10.1002/acp.1061

Li, C.-L., Aivar, M. P., Kit, D. M., Tong, M. H., \& Hayhoe, M. M. (2016).

López-Sastre, R. J., García-Fuertes, A., Redondo-Cabrera, C., Acevedo- Rodríguez, F. J., \& Maldonado-Bascón, S. (2013). Evaluating 3D spatial pyramids for classifying 3D shapes. Computers and Graphics (Pergamon), 37(5), 473-483. https://doi.org/10.1016/j.cag.2013.04.003

Maher, M. Lou, \& Kim, M. J. (2006). Studying designers using a tabletop system for 3D design with a focus on the impact on spatial cognition. In Proceedings of the First IEEE International Workshop on Horizontal Interactive Human-Computer Systems, TABLETOP'06 (Vol. 2006, pp. 105-112).

Markson, L., \& Paterson, K. B. (2009). Effects of gaze-aversion on visual-spatial imagination. British Journal of Psychology, 100(3), 553-563. https://doi.org/10.1348/000712608X371762

Marsh, T., \& Watt, A. (2016). Shape your imagination: iconic gestural-based interaction. Proceedings. IEEE 1998 Virtual Reality Annual International Symposium (Cat. No.98CB36180), (January), 122 125. https://doi.org/10.1109/VRAIS.1998.658465

Memory and visual search in naturalistic 2D and 3D environments. Journal of Vision, 16(8), 9. https://doi.org/10.1167/16.8.9

Pollefeys, M. (2004). Visual 3D Modeling from Images. Vmv, 143. https://doi.org/10.1002/vis.289

Pollefeys, M., \& Van Gool, L. (2002). Visual modelling: From images to images.

Proceedings of the Fifth Conference on Australasian User Interface - Volume 28, 28, 25-31. https://doi.org/10.1109/INFVIS.2001.963291

Rahimian, F. P., \& Ibrahim, R. (2011). Impacts of VR 3D sketching on novice designers' spatial cognition in collaborative conceptual architectural design. Design Studies, 32(3), 255-291. https://doi.org/10.1016/j.destud.2010.10.003

Redondo-Cabrera, C., Lopez-Sastre, R. J., Acevedo-Rodriguez, J., \& Maldonado- Bascon, S. (2012). SURFing the point clouds: Selective 3D spatial pyramids for category-level object recognition. In Proceedings of the IEEE Computer Society Conference on Computer Vision and Pattern Recognition (pp. 3458-3465). https://doi.org/10.1109/CVPR.2012.6248087

Sprague, K. B., \& de Kemp, E. A. (2005). Interpretive tools for 3-D structural geological modelling part II: Surface design from sparse spatial data.

Todd, J. T. (2004). The visual perception of 3D shape. Trends in Cognitive Sciences. https://doi.org/10.1016/j.tics.2004.01.006

Tory, M., Kirkpatrick, A. E., Atkins, M. S., \& Moller, T. (2006). Visualization task performance with 2D, 3D, and combination displays. IEEE Transactions on Visualization and Computer Graphics, 12(1), 2-13. https://doi.org/10.1109/TVCG.2006.17 